\title{
Biosafety in Public Health Emergency: China's Path and Global Governance
}

\author{
By CHEN YONGQIANG, PhD
}

\section{THE URGENCY OF BIOSAFETY GLOBAL GOVERNANCE IN A PUBLIC HEALTH EMERGENCY}

$\mathrm{P}$ UBLIC HEALTH IS THE SCIENCE and art of effectively preventing and containing diseases, maintaining and promoting health through organized social interventions. The outbreak of a novel coronavirus disease starting in January 2020 has been considered the sixth international public health emergency announced by the World Health Organization (WHO) since the implementation of the 2005 international health regulations. WHO has named this novel coronavirus as SARS-CoV-2 and the disease it causes as COVID-19. ${ }^{1}$

So far, COVID-19 has spread throughout China and a large number of other countries, among which cases are imported from each other. On January 31, 2020, the United States announced that the novel coronavirus epidemic in the United States constitutes a national public health emergency. On February 28, 2020, Dr. Tedros Adhanom Ghebreyesus, Director-General of WHO, said in Geneva that first cases had been reported in Denmark, Estonia, Lithuania, Holland, and Nigeria, all related to Italy. Twenty-four cases in 14 countries are related to Italy, and 97 cases in 11 countries are related to Iran, according to the reported data from various countries. ${ }^{2}$ On February 28, Dr. Tedros Ghebreyesus raised the level of global risk from this novel coronavirus to "very high."

Keywords: public health emergency; global governance; biosafety; China's path

Chen Yongqiang, PhD of Law, is a Professor at the Law School of China Jiliang University in Hangzhou, China. E-mail for Dr. Yongqiang: qufei1213@sina.com
As of the morning of March 8 Beijing time, other than the accumulated number of 80,859 confirmed cases in China, 21,989 people in 94 other countries and regions and a cruise ship have been reported to be infected with the virus, including over 7,000 in South Korea and over 5,000 both in Italy and Iran. ${ }^{3}$ While the epidemic in China has gradually been contained, the outbreak outside China is becoming serious. On March 7, 2020, the few newly confirmed cases in Chinese cities other than Wuhan were imported from other countries. ${ }^{4}$ Facing this international public health emergency, every country has the obligation to do a good job in epidemic prevention and containment. It is not only a test of China's national governing system and capacity, but also a test of the global governance capacity.

With the spread of the disease in many countries, it is urgent for all countries to unite as soon as possible to establish a cooperative mechanism to fight it together. It also provides a great opportunity for countries to work with each other and with WHO

${ }^{1}$ Naming the Coronavirus Disease (COVID-19) and the Virus That Causes It, World Health Organization (Feb. 2020), https://www.who.int/emergencies/diseases/novelcoronavirus-2019/technical-guidance/naming-the-corona virus-disease-(covid-2019)-and-the-virus-that-causes-it

${ }^{2}$ World Health Organization Coronavirus Disease (COVID-19) Press Conference (Feb. 28, 2020), https://www.who.int/ docs/default-source/coronaviruse/transcripts/who-audio-emer gencies-coronavirus-press-conference-full-28feb2020.pdf?sfv rsn=13eeb6a4_2

${ }^{3}$ Daily update by Tencent News, one of China's giant internet medias [in Chinese]. Available at: https://news.qq.com/zt2020/ page/feiyan.htm\#/global

${ }^{4}$ National Health Commission of the People's Republic of China: Update on Novel Coronavirus Epidemic as of 24:00, March 7, 2020 [in Chinese]. Available at: http://www.nhc.gov .cn/xcs/yqtb/202003/b4c328ff60874b99ba6ce8caf827987b .shtml 
in carrying out good cooperation and building an international order for epidemic prevention. From the perspective of a community with a shared future for mankind, all countries should undertake and fulfill the common anti-epidemic obligation, jointly promote the international cooperation of national public health governance, and improve the system of global public health management.

\section{CHINA'S EPIDEMIC CONTAINMENT: RESPONSE AND PATH}

The outbreak of COVID-19 in Wuhan, China, is considered to be a major public health emergency in China with the highest speed of spreading, the widest range of infection, and the most difficultly in prevention and containment since the founding of the People's Republic of China. The disease was included in the Category B infectious diseases in China after the outbreak of the Wuhan epidemic and was strictly contained according to the standard for Category A infectious diseases. The whole country has carried out nationwide anti-epidemic mobilization to strengthen people's contribution to containment and confidence. A top-level design of epidemic prevention and containment was emphasized, a nationwide unified deployment was adopted, and a unified epidemic-containment system was built up.

The Chinese government keeps strengthening unified deployment and command in top-level design. A series of general requirements and ideas were raised as follows: "prevent proliferation inside the country and exporting to other countries"; "discover early, report early, quarantine early, diagnose early, and treat early"; "manage in closed loops, assess in numbers, and manage with precision." From the perspective of scientific containment and precise policy implementation, the central government requires governments at all levels to take the responsibility of epidemic containment and institute workable measures to implement epidemic monitoring, investigation, early warning, prevention, and containment. With the development of the epidemic, the local governments of various provinces and cities in China immediately made a level-1 response to this major public health emergency. ${ }^{5}$

Within China's basic-level governing system, in the face of the epidemic, the strictest measures have been taken to control sources of infection; strictly quarantine confirmed cases, suspected cases, and close contacts; and expeditiously discover and quarantine sources of infection. Through the use of big data and network management means, information regarding infectious sources and people who have been to the epidemic area in the past month can be precisely identified.

At the level of rural villages and urban communities in China, self-governing management is carried out by the populace so that they would consciously abide by the containing measures during the epidemic containment period. People have been warned to go out less and to go through the procedure of registration and body temperature measurement before entering any residential community. Unnecessary public gatherings have been prohibited so as to minimize the chance of contamination. People are guided to enhance their self-protection awareness, and are encouraged to wear masks and wash their hands frequently. Patients' families are required to promptly report their conditions, take the initiative to quarantine, and cooperate with the treatment. In this people's war against COVID-19, the important role of social health institutions, community workers, community security force, and all families in preventing the expansion of the epidemic has been demonstrated.

Preventing and containing actions in crucial sites including airports, wharves, railway stations, bus stations, etc., are emphasized. Body temperature is measured for every passenger. Vehicles are registered. After the Spring Festival, when a huge number of people were leaving their hometowns and going to cities where they work, measures were taken to check their health conditions. In some places, the digital health coding system has been adopted. With the help of a questionnaire and big data about a person's whereabouts, personal health information is presented through color coding. If a person's health code is green, they can go everywhere that is open; if it is red, a person cannot go out and need to quarantine themselves for 14 days. In the case of conflict between personal interests and public interests, citizens shall respect the public interests and cooperate with containment measures so as to help maintain public security.

As for curing the disease, the Chinese government has been continuously releasing and adjusting plans of diagnosis and treatment. Treatments with the cooperation of traditional Chinese medicine and modern medical science have been adopted to ensure the best help to patients. Hospitals throughout the country learn about each other's treatment

\footnotetext{
${ }^{5}$ According to the Law of the People's Republic of China on Response to Emergencies, public health events are divided into four categories: Particularly Significant, Significant, Large, and General. Level-1 response is to deal with Particularly Significant public health events.
} 
plans to enhance their own curing abilities. Patients are treated in designated hospitals, while severe cases are treated by the most capable expert groups. In terms of medical materials supply, the whole country has been distributing ambulances, wards, medicines, disinfectant, testing reagents, medical devices, protective equipment, and other medical materials in a unified way. Designated hospitals and backup hospitals, such as medical shelters, were built up quickly. For medical materials in short supply, donations have been made through the Red Cross and other social charity organizations to support areas stricken by the epidemic. To relieve the pressure upon medical staff in Wuhan, the epicenter with the largest number of cases, the state has also set up a model of urban mutual assistance, sending medical teams to Wuhan in different times. Around 42,600 medical and nursing professionals in 346 teams from all over the country have been organized and dispatched to help Wuhan and other cities in Hubei province. ${ }^{6}$

In terms of scientific research, the country temporarily set up an urgent scientific research task; organized strategic and interdisciplinary scientific research teams; determined the five main research directions (clinical treatment and medicines, vaccine research and development, detection technology and products, viral etiology and epidemiology, and animal model construction); coordinated scientific research, clinical research, prevention and containment; and closely coordinated the producing, learning, and research parties to provide scientific and technological support for epidemic prevention and containment. Through scientific research, the origin of the virus and the way of its spreading can be determined, the variation of the virus can be tracked, and strategies and measures for prevention and containment can be adjusted over time. Simultaneously, relevant data and case descriptions are shared to speed up research on the origin of the virus, its spreading ability, and spreading mechanism.

With regard to epidemic information disclosure, the central government has established an official unified reporting system and information release platform, updating the public with case numbers in all cities on a daily basis to keep them informed. Some places, like Zhejiang Province, publicize every confirmed case's timeline around the infection. The government has strictly prevented the spread of false information among people to avoid unnecessary panic and has punished those who fabricate rumors. Medical experts provide explanations to the public to improve their understanding of the disease, and to respond to their concerns and questions about the situation and measures taken.
After the outbreak of the disease, due to the strict quarantine measures, businesses were closed temporarily and markets were shut down, which might make it difficult for people to obtain daily necessities. Local governments played their roles in overall planning and promoting supplies through e-commerce platforms so as to ensure the supply of daily necessities for the people. Supervision has been strengthened over transactions involving masks, medicines, vegetables, rice, and other daily necessities. Price control has been implemented to keep prices from soaring, and those who took advantage of the opportunity to drive up prices were sanctioned so as to prevent and regulate market disorder. Wild animals that may carry viruses, such as bamboo rats and badgers, have been confiscated from dealers and quarantined, and are prohibited from being transported and entering the market, so as to prevent the further spreading of the virus from the original source.

As the virus that caused the epidemic may come from wildlife, the Chinese government proposed to protect public health through relevant lawmaking. Legislative bodies were required to evaluate the amendment and improvement of such laws and regulations as the Law of the People's Republic of China on the Prevention and Treatment of Infectious Diseases and the Law of the People's Republic of China on Protection of Wildlife. Biological safety was suggested to be integrated into the national security system, and the establishment of a law on biological safety was accelerated. On February 24, the Standing Committee of the National People's Congress launched the legislative process, passed the Decision on Banning Illegal Trade of Wildlife, Eliminating the Bad Habit of Eating Wildlife, and Ensuring People's Health and Safety. Thus, a system of banning eating wildlife in an all-round way was established. The Decision made it clear that hunting, trading, and transportation of wildlife for the purpose of eating must be strictly prohibited in accordance with Law of the People's Republic of China on Protection of Wildlife and other laws. It is prohibited to eat "terrestrial wildlife with important ecological, scientific, and social values" and other terrestrial wildlife under state protection, including those artificially bred and raised by human beings.

\footnotetext{
${ }^{6}$ Guo Yanhong, Supervisor from Medical Administration Bureau of National Health Commission of the People's Republic of China, reported at the press conference of the Joint Prevention and Control Mechanism of the State Council on March 8, 2020. A video clip of the content [in Chinese] is available at https://video.sina.cn/news/2020-03-08/detailiimxxstf7368050.d.html?vt=4\&wm=3049_00051270939248
} 
The law prohibits hunting, trading, and transporting terrestrial wildlife that grow and breed naturally in the wild environment for the purpose of eating. Any violation of the above provisions shall be punished or severely punished.

China regards the epidemic as a battle. In one and a half months from the closure of Wuhan on January 23,2020 , the number of newly confirmed cases in Wuhan on a daily basis experienced sharp increases at the early stage, but has dropped rapidly in recent days, while very few new cases have been found outside Wuhan. Within 24 hours of March 6,2020 , the number of new cases in Wuhan first dropped to below 100, and on March 7, it further dropped to 41. At the same time, the few new cases outside the city throughout China were all imported from other countries instead of being propagated in the community. ${ }^{7}$

The effectiveness of the epidemic prevention and containment is undeniably huge, and China's systematic efforts in combating the epidemic is internationally recognized. Experts from WHO said that China has taken the bravest, most flexible, and most active containment measures in history. China's response to the epidemic and its measures to combat it are both large-scale and flexible. There is not only large-scale social mobilization at the national level to keep people physically distant from each other, but also monitoring the spread of the virus using communication technologies, such as $5 \mathrm{G}$. The spreading curve of this new coronavirus with lethal risk has been changed. China's comprehensive intervention measures to cut off the virus's spread have been very effective and have provided important experience for the global community to respond to the new coronavirus epidemic. These measures include: proactive testing, rapid discovery and immediate diagnosis, quarantine of confirmed cases, strict tracking and quarantine of close contacts, and guiding the public to understand and accept the above measures. The world also needs to learn from China's experience to combat the epidemic.

On the other hand, China's public health emergency management system also shown some shortcomings and weaknesses during the outbreak of this disease. At present, there are eight functional subsystems of China's public health system, including disease prevention and containment, health education, maternal and children health care, mental health, emergency treatment, blood collection and supply, health supervision, and family planning. However, the subsystem of disease prevention and containment is not gaining enough attention, the degree of modernization is not high enough, and investment in public medical and health institutions needs to be further increased. The role of social groups, especially various professional societies, can be increased to a further extent. The differentiation of tasks and coordination among professional public health institutions, professional medical institutions, and nonprofessional government bodies and social groups in the process of discovery, early warning, and emergency management need to be further strengthened. In the future, China needs to strengthen the construction of a system of general practitioner training and hierarchical diagnosis and treatment, promote the efficient coordination of public health services and medical services, and improve the public health management system.

Public safety in the domain of healthcare is a common challenge facing mankind. It requires all countries to work together to cope with it. We need to strengthen communication and exchange with the World Health Organization; share scientific research data and information with relevant countries, especially countries with a serious epidemic, in terms of origin tracing, medicines, vaccines, testing, etc.; study jointly to work out useful strategies; and contribute wisdom and theory to the construction of a community with a shared future for mankind.

\section{GLOBAL GOVERNANCE MECHANISM OF PUBLIC HEALTH EMERGENCIES}

With today's globalization, the prevention and containment of infectious diseases is not the responsibility of a single country, but the common responsibility and obligation of the whole world. International cooperation in biosafety is very necessary. The international community should establish an open, transparent, sharing, and mutual assisting response system.

The main body of global public health governance is various countries and international organizations. A set of international cooperation mechanisms should be established between them, which should include a set of principles, norms, rules, and decision-making procedures to deal with threats to public health. In this way, in the emergency of a disease outbreak or in the monitoring stage before such an outbreak, the international

\footnotetext{
${ }^{7}$ National Health Commission of the People's Republic of China: Update on Novel Coronavirus Epidemic as of 24:00, March 7, 2020 [in Chinese]. Available at: http://www.nhc.gov .cn/xcs/yqtb/202003/b4c328ff60874b99ba6ce8caf827987b .shtml
} 
community will be able to jointly launch this response mechanism, so as to regulate and restrict the epidemic containment actions of various countries, timely and accurately notify each other of any epidemic information, increase mutual trust, and reduce the cost of information collection. Thus, the process of global efforts in responding to an epidemic will be under control, actions taken will be more scientific, and it will be more likely for human beings to win the battle of epidemic containment.

Countries should actively participate in international cooperation in the domain of public health. In case of an epidemic, countries should launch emergency response mechanisms in time, including the identification and registration of people from affected areas, the detection and registration of international flights, railways, ships, and other entry-exit checkpoints, so as to ensure the control of the epidemic and the traceability of affected people. But we should also avoid discrimination against countries and people from the epicenter and other affected areas. Some countries have initiated measures to restrict entry, and discrimination against people from specific epidemic areas happens from time to time. This is not conducive to the prevention and containment of the epidemic. Instead, it undermines the good cooperation between countries in public health events.

From the diplomatic perspective, all countries should adopt a more active diplomatic strategy regarding public health issues to help and support the affected countries with a humanitarian spirit, rather than simply restricting or discriminating against them. Human beings live on the same earth and have a common home. In the era of globalization, people interact with each other, and international trade, tourism, culture, and health are all interdependent. We cannot ignore the public health risks in other countries. In particular, as Ms. Hou Li points out, the deepening of globalization and interdependence should not be seen by rich countries as a purely economic phenomenon that enables enterprises to carry out manufacturing and supply chain operations in low- and middle-income economies. Countries with economic advantages also have the responsibility to establish support mechanisms to help other countries cope with emerging threats to public health. ${ }^{8}$

The international community needs to put forward common efforts to establish a global public health early warning mechanism and a public health monitoring mechanism. The global early warning mechanism can help countries adopt emergency mechanisms immediately at the beginning of the outbreak. On the one hand, it can ensure that they are fully prepared for the outbreak, and on the other hand, it can effectively avoid social disorders caused by large-scale infection due to untimely information. The global health inspection mechanism can help people understand the situation in their own country and in the world, so as to effectively avoid panic. It can also provide guidance to relevant global industries and investors, increase the ability of the affected country to distribute materials and other infrastructure, and effectively reduce the impact of the epidemic on people's health and livelihood and on the economy.

A global public health early warning mechanism and public health monitoring mechanism means a kind of digital public health governance, which is based on big data and network technology. Countries should start to build and improve the "public health early warning and response network" covering the whole country as soon as possible, set up a "disease monitoring electronic system," monitor the occurrence and development of any epidemic through real-time monitoring of medical records, build a "public health information network system," analyze public health information in real time through algorithms and big data, and provide a reliable basis for scientific decision making.

At the national level, on the basis of building a sound public health information and reporting system, when an epidemic occurs, it is necessary to timely report the epidemic information to the international community and international organizations, make an early warning to $\mathrm{WHO}$, and share data related to the epidemic. The world should establish a public health event response mechanism, and adopt a series of response systems for affected countries and everyone around the world. The World Health Organization will then be able to notify and warn the world early according to the epidemic situation, spreading speed, virus characteristics, and other information, and immediately launch a series of measures such as virus investigation, medicine research and development, equipment assistance, and medical assistance. The World Health Organization will fulfill the task of global epidemic containment as the commander in chief, and function as an information center, data center, scientific research center, medical diagnosis and treatment center, medical assistance center, etc. The World Health Organization should establish a medical expert group in time to conduct comprehensive

\footnotetext{
${ }^{8} \mathrm{Hou} \mathrm{Li}$, Improve the Global Public Health Management Ability [in Chinese], Chinese Social Sciences Today, Volume 1875, page 3. February 28, 2020.
} 
studies on the virus, its spreading characteristics, and treatment plans. Countries should provide research funds for the World Health Organization.

The global public health management system is one of multi-party participation, equal consultation, and joint governance. Global public health governance should become a normalized issue. Governments and the public must change their ideas and actions, and take public health governance seriously. The focus of public health governance is prevention. Only through constant academic research, repeated participation in discussion, and open, equal consultation can we promote the formation of a changing international public health management system. Countries should attach importance to public health and biosafety at the level of national security strategies; strengthen talent training; increase financial input; establish a hierarchical diagnosis and treatment system; improve emergency management systems; strengthen governing capabilities in disease control, testing, and prevention, virus research, medicine research and development, material supply, etc.; and fulfill the common obligation of improving global biosafety. 